\title{
SIMULASI PERFORMANSI EVAPORATOR SISTEM MESIN PENDINGIN SIKLUS ADSORPSI MENGGUNAKAN PERANGKAT LUNAK ANSYS 17.0
}

\author{
Muhammad Arif ${ }^{1 *}$, Tulus B. Sitorus ${ }^{2}$, Dian M. Nasution ${ }^{3}$, Pramio G. Sembiring ${ }^{4}$ \\ 1,2,3,4 Departemen Teknik Mesin, Fakultas Teknik, Universitas Sumatera Utara \\ Email: mumd.arif291195@gmail.com
}

\begin{abstract}
In the world of technology industry, the use of prototypes that are made will take a long time and cost a lot in operating system performance, analyzing the treatment of the system, and giving decisions from the results of the analysis. Therefore, the search for alternative technologies from prototypes that support the industrial world improves system performance by providing ways to design and design decisions, as well as better management. One alternative technology is found, namely CFD applications. CFD applications are widely used in the field of science, including in terms of the evaporationcondensation process. The purpose of this study is to determine the fluid phenomena that occur in the evaporator system on the use of adsorption cooling devices. Simulations are carried out in transient conditions, carried out at 18:00 WIB when the adsorption process occurs. The evaporator uses Aluminum material thickness of $3 \mathrm{~mm}$ and uses methanol fluid as its refraction. Simulation results are displayed in the form of contours, images and videos. Based on empirical calculations, the amount of evaporator efficiency that occurs is $78.4 \%$.
\end{abstract}

Keywords: CFD, Evaporataion-condensation, Evaorator, Adsorption

\section{Abstrak}

Dalam dunia industri teknologi, penggunaan prototype yang dibuat akan memakan waktu yang lama dan biaya yang besar dalam pengoperasian kinerja sistem, analisa perlakuan terhadap sistem, dan memberikan keputusan dari hasil analisa. Oleh sebab itu, dilakukan pencarian teknologi alternatif dari prototype yang menunjang dunia industri meningkatkan kinerja sistem dengan menyediakan cara untuk membuat rancangan dan keputusan rancangan, serta manajemen yang lebih baik. Ditemukan salah satu teknologi alternatif yaitu aplikasi CFD. Aplikasi CFD banyak digunakan dalam bidang ilmu, diantaranya dalam hal proses evaporasi-kondensasi. Tujuan dilakukannya penelitian ini adalah untuk mengetahui fenomena fluida yang terjadi didalam sistem evaporator pada penggunaan alat pendingin adsorpsi. Simulasi dilakukan pada kondisi transien, dilakukan pada waktu 18:00 WIB saat proses adsorpsi terjadi. Evaporator menggunakan bahan Aluminium ketebalan $3 \mathrm{~mm}$ dan menggunakan fluida metanol sebagai refrijeran nya. Hasil simulasi ditampilkan dalam bentuk kontur, gambar dan video. Berdasarkan perhitungan empiris, besar efisiensi evaporator yang terjadi adalah sebesar $78,4 \%$. 
Kata kunci: CFD, Evaporasi-kondensasi, Evaporator, Adsorpsi

\section{Pendahuluan}

Evaporator merupakan komponen penting bersama dengan komponen utama lainnya dalam sistem pendingin seperti kompresor, kondensor, dan perangkat ekspansi [1]. Pentingnya untuk pendinginan adalah untuk menghilangkan panas dari udara, air atau zat lainnya. Di sinilah refrijeran cair diperluas dan menguap. Cairan refrijeran dalam evaporator bertindak sebagai penukar panas yang mentransfer panas dari zat yang didinginkan ke suhu mendidih.

Selama bertahun-tahun Computational Fluid Dynamics (CFD) telah menjadi alat simulasi standar untuk desain, analisis, kinerja sistem dan analisis sistem teknik tentang aliran fluida [2]. Peningkatan ini telah didorong oleh kecepatan kemajuan komputer, sistem yang terjangkau dan kemudahan ketersediaan perangkat lunak CFD komersial baru yang mengarah ke stabilitas penurunan biaya simulasi CFD dibandingkan dengan percobaan prototype [3]. Dengan metode seperti CFD akan mungkin untuk mendapatkan pandangan mendalam dari sistem sebagai bahan inovasi dari sebuah perancangan [4].

Sementara, penelitian dan perkembangan dari teknologi pendingin adsorpsi memerlukan waktu dan biaya yang tidak sedikit. Oleh karena itu, untuk mengurangi waktu yang dibutuhkan dalam pengembangan dan mengurangi biaya pengembangan diperlukan teknologi simulasi. Dengan melibatkan aliran fluida, bidang CFD (Computational Fluid Dynamics) dapat digunakan untuk membantu pemodelan proses perubahan fasa (volume fraction). Akhir-akhir ini, CFD semakin banyak digunakan untuk melakukan analisa pemodelan simulasi. Program CFD merupakan salah satu teknologi simulasi yang dapat digunakan untuk melakukan penelitian dalam menganalisis permasalahan pada proses adsorpsi.

Tujuan dilakukannya penelitian ini adalah untuk mengetahui temperatur minimum air dan metanol, mengetahui volume metanol yang dapat menguap saat proses adsorpsi dan desorpsi, mengetahui fenomena fluida (temperatur dan tekanan) yang terjadi pada simulasi, dan mengetahui terjadinya perpindahan panas dalam model tiga dimensi dari sistem evaporator.

\section{Metode}

Penelitian ini dilakukan di lantai 4 gedung Magister Teknik Mesin Universitas Sumatera utara. Jenis evaporator yang digunakan pada pengujian mesin pendingin siklus adsorpsi menggunakan tenaga surya seperti gambar 2.1 dibawah ini: 


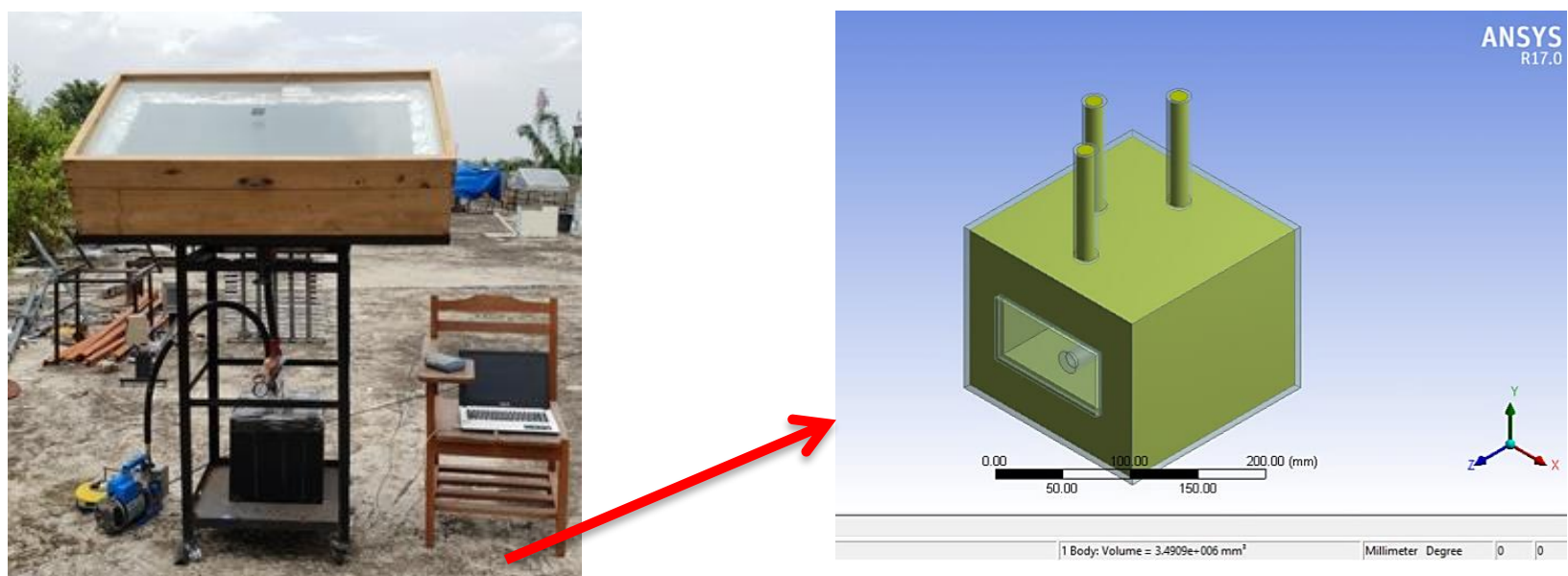

Gambar 2.1 Mesin pendingin siklus adsorpsi dan komponen evaporator

\subsection{Metode Numerik}

Aliran dua fasa dengan model 3-dimensi yang dibangun pada simulasi dengan proses evaporasi-kondensasi pada komponen evaporator mesin pendingin siklus adsorpsi. Bahan evaporator yang digunakan adalah aluminium dan metanol sebagai refrijerannya, simulasi dalam kondisi transien dan gaya gravitasi ditambahkan dalam simulasi dalam arah vertikal.

1. Konservasi Massa [5]

$$
\frac{\partial \rho}{\partial t}+\frac{\partial}{\partial x_{i}}\left(\rho u_{i}\right)=0
$$

Dimana $x_{i}, i=1,2,3$ menunjuk ke sumbu $x, y, z$ berturut-turut.

2. Konservasi Momentum, dan

$$
\frac{\partial\left(\rho u_{i}\right)}{\partial t}+\frac{\partial\left(\rho u_{i} u_{j}\right)}{\partial x_{j}}=-\frac{\partial p}{\partial x_{i}}+\frac{\partial}{\partial x_{j}}\left[\mu\left(\frac{\partial u_{i}}{\partial x_{j}}+\frac{\partial u_{j}}{\partial x_{i}}\right)-\frac{2}{3} \delta_{i j} \mu \frac{\partial u_{k}}{\partial x_{k}}\right]+\rho f_{i}
$$

Dimana $i, j, k=1,2,3$ mengarah ke sumbu $x, y, z$ secara berturut-turut.

3. Konservasi Energi

$$
\frac{\partial(\rho c T)}{\partial t}+\frac{\partial(\rho c T)}{\partial x_{i}}=\frac{\partial}{\partial x_{i}}\left(k \frac{\partial T}{\partial x_{i}}\right)-p \frac{\partial u_{i}}{\partial x_{i}}+\rho \dot{q}+\Phi
$$

Dimana $i, j, k=1,2,3$ sebagai sumbu $x, y, z$. 


\subsection{Skema Eksperimental}

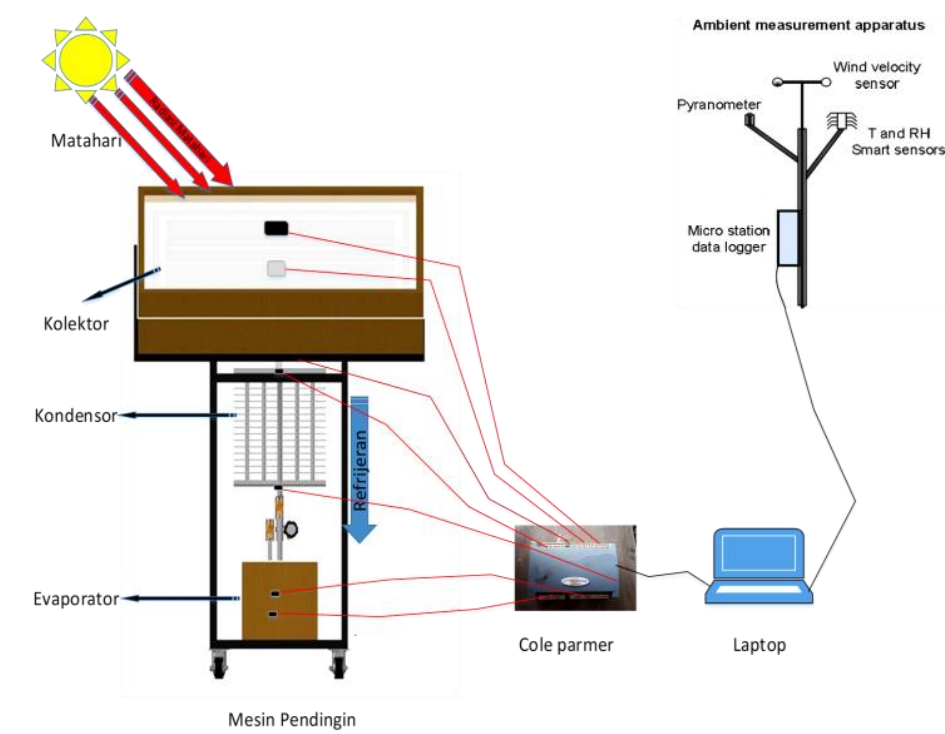

Gambar 2.2 Skema penelitian mesin pendingin siklus adsorpsi

Proses desorpsi pada pukul 08.00 - 17.00 WIB terjadi karena panas yang di dapat dari sinar matahari berpindah secara radiasi ke Kolektor. Refrigerant yang berada di Kolektor yaitu karbon aktif akan menimbulkan uap desorpsi, uap ini akan mengalir ke Evaporator melalui selang, dan uap ini akan berubah fasa menjadi cair di dalam Evaporator.

Kemudian pada pukul 17.00 - 08.00 WIB kolektor melepaskan panas, sehingga kolektor mengalami penurunan temperatur dan tekanan yang menyebabkan timbulnya uap adsorpsi. Adsorbat dalam bentuk uap mengalir dari evaporator ke kondensor dan kemudian ke kolektor. Adsorbat dalam bentuk uap di hasilkan dari proses penyerapan kalor oleh adsorbat dari lingkungan sebesar kalor laten penguapan adsorbat tersebut. Proses ini berlangsung pada tekanan saturasi yang rendah sehingga penyerapan kalor berlangsung pada tekanan yang rendah pula. Proses tersebut dinamakan adsorpsi.

\section{Analisis dan Pembahasan}

\subsection{Kondisi Batas}

Simulasi dilakukan selama 30 menit dari proses adsorpsi, pengambilan data simulasi dimulai pada pukul 18:00 WIB. Kondisi batas evaporator dibagi kedalam dua bagian yaitu, bagian evaporator sebagai solid dan dalam evaporator sebagai fluida. Bahan evaporator adalah aluminium, fluida yang digunakan adalah metanol-liquid, bagian uap keluar evaporator 
didefinisikan sebagai pressure-outlet. Berdasarkan data pengujian, temperatur metanol sebesar 299K, temperatur botol sebesar 296.3 K, tekanan sebesar $79993.42 \mathrm{~Pa}$, dan besar percepatan gravitasi yang digunakan adalah $9.81 \mathrm{~m} / \mathrm{s}^{2}$.

\subsection{Hasil Simulasi}

Pembuatan geometry evaporator menggunakan AutoCAD 2016, simulasi dilakukan menggunakan software Ansys 17.0. simulasi menunjukan fenomena fluida yang terjadi pada evaporator dalam proses evaporasi untuk mendinginkan air di dalam botol. Gambar-gambar menunjukkan hasil simulasi selama 30 menit.

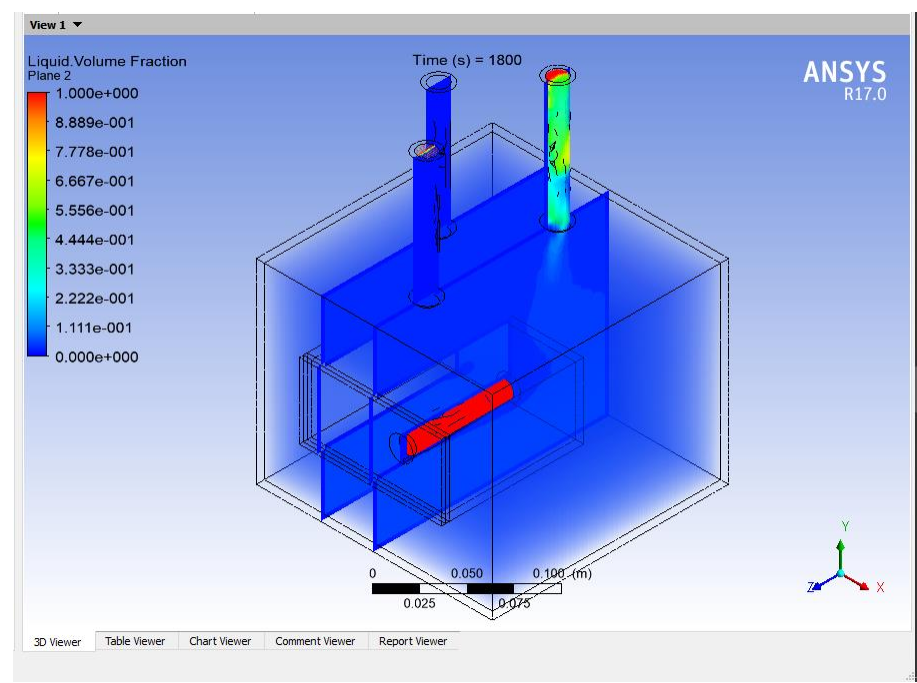

Gambar 3.1 Liquid volume fraction selama 30 menit

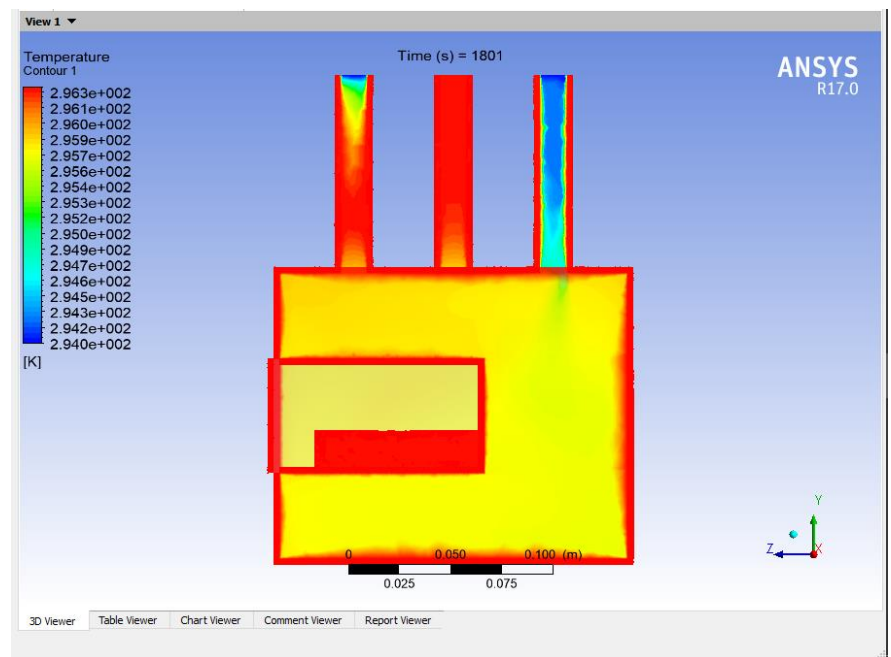

Gambar 3.2 Distribusi temperatur selama 30 menit 


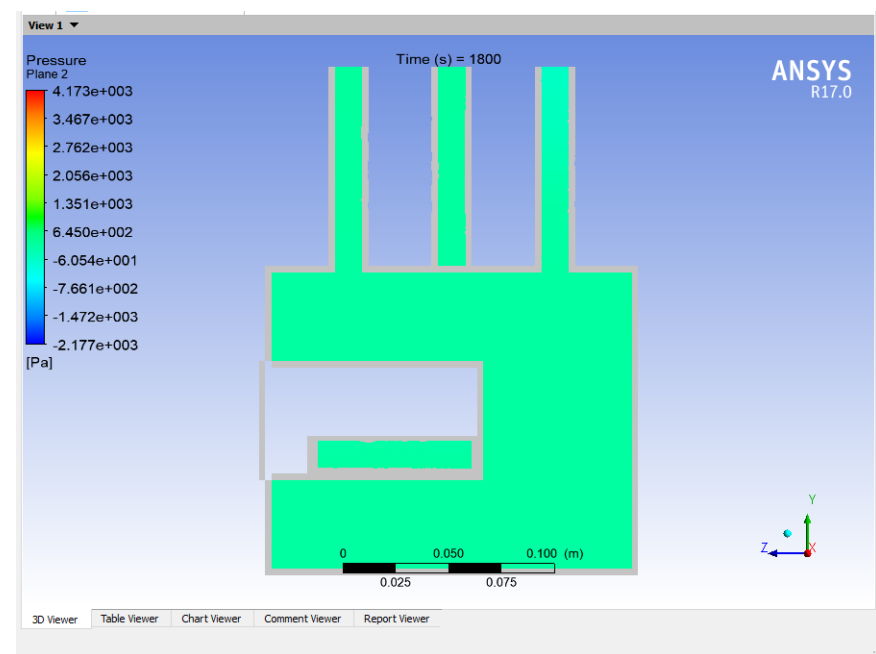

Gambar 3.3 Distribusi tekanan selama 30 menit

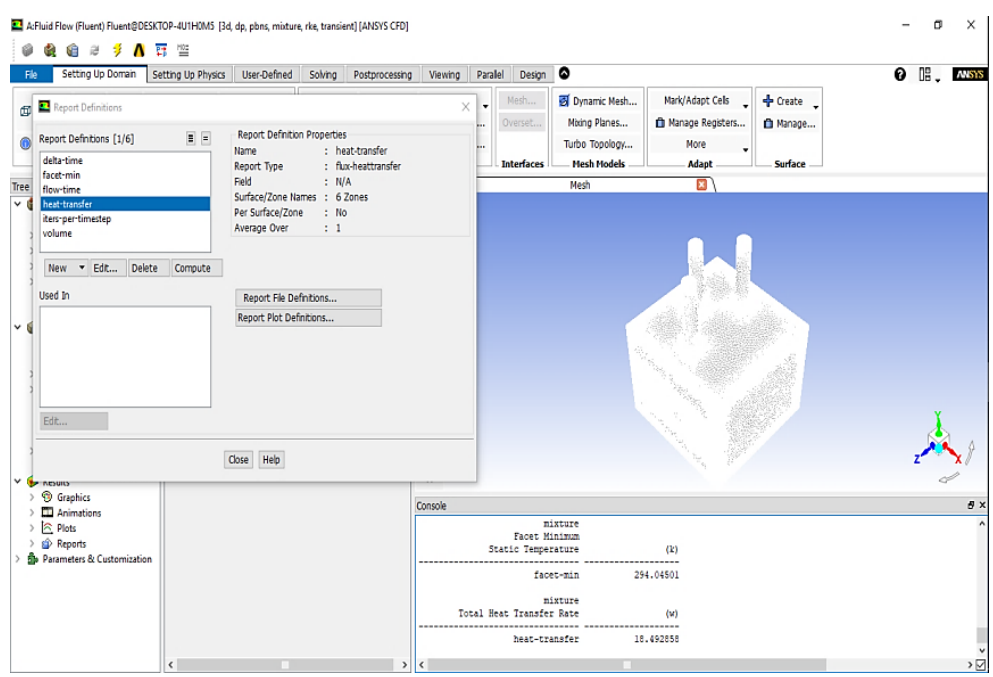

Gambar 3.4 Besar laju perpindahan panas evaporator selama 30 menit

\section{Kesimpulan}

Simulasi menggunakan aliran dua fasa yaitu dari proses liquid menjadi uap, dalam simulasi digunakan proses evaporasi-kondensasi. Dari hasil simulasi yang dilakukan selama 30 menit, jumlah volume metanol yang menguap dari pukul 18:00 Wib sebesar $0.000148 \mathrm{~m}^{3}$ tertuju pada gambar 3.1, dan besar laju perpindahan panas yang terjadi pada evaporator sebesar 18 Watt (gambar 3.4). Simulasi menunjukkan bagaimana proses terjadinya evaporasi. Efisiensi 
evaporator dihitung dengan menggunakan persamaan-persamaan diperoleh sebesar $78 \%$ dengan temperatur minimum air $0.36^{\circ} \mathrm{C}$.

\section{Referensi}

1. Kinerja Kolektor Tipe Plat Datar pada Mesin Pendingin Adsorpsi Tenaga Surya di Kota Medan Jurnal TeknoSains, Pascasarjana UGM Yogyakarta, Volume 7, Nomor 2, Juni 2018.

2. Augier. F., Laroche C., Brehon E. 2008. Application of Computational Fluid Dynamics to Fixed Bed Adsorption Calculations. Beijing: University of Science and Technology.

3. T. B. Sitorus, The performance of a solar collector on adsorption refrigerator, IOP Conf. Series: Journal of Physics: Conf. Series 1114 (2018) 012015.

4. Nuntaphan Atipoang, Vithayasai Sanparwat, Vorayos Nat, dkk. 2010. Use of Oscillating Heat Pipe Technique as Extended Surface in Wire on Tube Heat Exchanger for Heat Transfer Enhancement. International Commucations in Heat and Mass Transfer.

5. Ambarita, H. Computational Fluid Dynamics. Medan: Mechanical Engineering Department. 